is reached that the essential part of the coronal lines is due to iron, nickel, calcium and argon atoms deprived of about half their normal electron envelope. Such a high state of ionization raises certain problems in solar phenomena, and various attempts have been made to give a physical explanation to established facts.

The existence of a high temperature in the corona is supported by a number of arguments, among which may be noticed the following, all of which point to a temperature exceeding a quarter of a million degrees : (1) the mean high state of ionization as revealed by the emission lines; (2) the breadth of the emission lines, if this is due to thermal Doppler effect, though macroscopic irregular motions or radial motions of matter might cause the broadening of the lines ; (3) the blurring out of the Fraunhofer lines in the continuous spectrum of the inner corona, assumed to be an effect of the velocities of the scattering electrons; (4) the absence of the Balmer lines in the emission line spectrum of the corona, explained by the electrons being too fast to be captured by the protons ; (5) dynamical considerations showing that great thermal velocities are necessary to balance the gravitational forces in order to explain the observed density gradient of the corona.

Reference is made to the theory of Alfvén that the corona might consist of particles with very high energy; Alfvén derived from the density function a temperature of about a million degrees. A quotation is given from Alfvén's work which explains the heating mechanism: "Motion of solar matter in magnetic fields on the sun, especially the vortical motion in a sunspot, must bring about a potential difference between different points of the solar surface, and it was shown that under certain conditions this gives rise to discharges above the surface of the sun. Calculations indicate that the electromotive force can be as high as $10^{7}$ volts, so that even if charged particles are usually accelerated only by a small fraction of this potential, they attain rather high energies. The process is most conspicuous in the prominences, where consequently we can expect a very intense production of high energy particles. As the mechanism is of a very general character the same process is likely to take place very frequently on a smaller scale. If-as many authors mean-we can regard the chromosphere as a multitude of small prominences, it is likely that a production of high energy particles takes place almost anywhere on the solar surface or in some layer above it."

Menzel held a different view of the origin of the highly ionized particles in the corona, and suggested that the coronal matter was ejected from the hot interior of the sun through holes and cracks on the surface. More recently, Vegard has expressed a somewhat similar opinion; he thinks that the highly ionized heavy ions in the corona come from the sun's deeper layers, being driven away from the sun at high speeds by means of the electric fields resulting from the photo-electric effect produced by soft $\mathrm{X}$-rays. Saha has suggested that the highly ionized atoms emitting the coronal lines are the fragments of a kind of nuclear fission occurring near the surface of the sun.

At present it would be unwise to pronounce in favour of any one of these views, and the physical explanation of the corona still remains a problem.

\author{
$T$
}

BROADCASTING IN GREAT BRITAIN HE British Broad forporion is at present operating enter the terms of a Royal Charter which campinto force on January 1, 1937, for a period of th years (see Nature, 139, $19 ; 1937$ ). In view $f e^{\circ}$ approaching expiration of this charter, the Government has given careful consideration to the Mrability of appointing an independent body to advise on the organisation of British broadcasting in the future. But it has been decided that such an inquiry would not be appropriate at the present time ; and that the charter and licence granted to the B.B.C. should be renewed, with certain alterations, for a period of five years from January 1, 1947.

The justification for this action is given in a White Paper* recently published. This paper forms a concise historical review of broadcasting in Great Britain, outlining the policy adopted throughout and the development and activities of the Home and Overseas Services up to and including the war years. On the matter of the appropriateness of an inquiry, it is stated that though the Government is not opposed in principle to the appointment of an independent committee, there are three main reasons for not doing this at the present time or even in one year's time. In the first place, since September 1939, the B.B.C. have been operating under completely abnormal conditions; and the existing charter and licence have therefore run for less than three years under normal conditions; this is an insufficient period to enable a sound judgment to be made of the merits or otherwise of the organisation established in 1937. Secondly, it is too early yet to see with any clarity the effects on peace-time broadcasting of the remarkable developments in the field of electronics and radiofrequency technique which have taken place during the past ten years. Thirdly, the broadcasting service in Britain must operate with due regard to the allocation of wave-lengths for all radio purposes by the International Telecommunications Union; and it will inevitably be some time before the existing agreements can be revised to take account of the geographical and technical changes of the past six years.

In renewing the charter and licence for a period of five years, the Government proposes to consider well in advance of the expiry of this period the desir. ability of appointing an independent committee to advise on future broadcasting. In the meantime, the B.B.C. will continue to provide its service as a public utility body which is ultimately responsible to Parliament, but which is free so far as possible to carry out its obligations without political interference or control. The Postmaster-General is responsible to Parliament for the broadcasting vote, while the Lord President of the Couneil now deals with all questions of major broadcasting policy.

The White Paper gives details of the distribution before and during the War of the wave-lengths available to Great Britain, and describes the present arrangement of national and regional stations, and the corresponding programmes. A third programme for Home listeners, intended to be received effectively by about 80 per cent of the population, will be introduced by the B.B.C. in the autumn. An obliga. tion has been laid on the Corporation to broadcast a * Broadcasting Policy. (Cmd. 6852.) Pp. 28. (London: H.M.
Stationery Office, 1946.) 6d. net. 
daily account of the proceedings of Parliament by professional reporters, while at the same time an impartial balance must be maintained between parties in all political broadcasting. The present prohibition of commercially sponsored programmes will be maintained, and the Government intends to take all steps within its power to prevent the direction of commercial broadcasts to Britain from abroad. The Empire Services of the B.B.C. are to be maintained and developed, while in addition, many of the foreign language broadcasts must be continued in support of British prestige and influence abroad. These overseas broadcasting services will, however, be financed by an annual grant-in-aid to the Corporation from public funds, so that the whole of the wireless licence net revenue will be available for the Home services.

In order to meet the cost of the post-war development of sound broadcasting programmes, the weekly duration of which is some 50 per cent above the prewar level, the Government has recently raised the annual charge for a wireless receiving licence, and introduced an additional charge for the domestic reception of television programmes. Apart from the provision of adequate service time, the Paper states that great importance is attached to improving the technical quality of broadcast transmissions to the public. It may confidently be expected, therefore, that for the next five years the broadcasting service in Great Britain will be maintained and improved, so that it will continue, as in the past, to bear favourable comparison with any other service in the world.

$$
1016
$$

\section{THE ACADEMY OF SCIENCES OF THE U.S.S.R.}

THE Academy of Scie mo of the U.S.S.R. was founded by Pet on treat on January 22, 1724 (Old Style), but of gd functioning on November 2, 1725 (Old Styl) alter Peter's death. Its establishment was fart of Peter the Great's scheme of widespreap cultural and industrial reforms intended to bring Russia into line with the Western European States. In the draft of the structure and functions of the Academy, Peter was guided by the examples of the Royal Society of London and the Paris Academy of Sciences. In commemoration of the 220th anniversary of its existence the Academy has published a substantial, well printed and handsomely illustrated volume entitled: "220 years of the Academy of Sciences of the U.S.S.R., 1945" (Moscow and Leningrad, Acad. of Sci. U.S.S.R., 1945). It is a pity that the book is published only in Russian, with no English or French version, for it provides detailed and easily accessible information concerning the structure of the Academy and its membership.

The introduction is historical. The original idea of Peter the Great was that the Academy should combine research and teaching activities, and this conception lasted until 1803. At first, as was natural, the Academy had few native workers, and the names of eminent foreigners, such as L. Euler and D. Bernoulli, occupy the field. M. V. Lomonosov (1711-65) opened up the road to a succession of brilliant workers in all branches of knowledge. These included M. V. Ostrogradsky (1801-61), P. L. Chebyshev (1801-94), A. M. Boutlerov (1828-86), N. N. Beketov (1827-1911), B. B. Golizyn (18621916), S. F. Oldenburg (1863-1934), A. A. Shach- matov (1864-1920), S. M. Soloviev (1820-79) and many others. But many prominent men of science, such as N. I. Lobachevsky and D. I. Mendeleev, were excluded from the Academy through the influence of the Government.

After the Revolution of 1917 the Academy grew rapidly : 1725 , 15 academicians ; 1925,48 academicians ; 1945,142 academicians and 208 corresponding members; and of these, 109 academicians and 137 corresponding members, together with some four thousand senior and junior scientific workers, are serving at the various institutions of the Academy. Before 1917, the Academy had five laboratories and five museums, and worked through fifteen committees. In 1945 it embraced fifty-three scientific institutes, possessed sixteen laboratories, thirty-five research stations, fifteen museums and eleven provincial sections and worked through thirty-one committees. All these dependent institutions are now grouped into eight sections: (1) physics and mathematics, (2) chemistry, (3) geology and geography, (4) biology, (5) technology, (6) history and philosophy, (7) economics and law, (8) literature and philology.

In addition to the large number of books published under its auspices, the Academy is responsible for some forty-four periodical, seventy-one non-periodical and nineteen serial publications, all of which are listed in this jubilee volume, as well as books specifically relating to the Academy, biographical, bibliographical and historical. There is also a brief but comprehensive account of every institute, laboratory, research station, museum, library, affiliated society and provincial section, and a short biographical note on each academician and corresponding member-in all, a magnificent work of reference to an ancient but remarkably vigorous and active society.

\section{S. I. TOMKEIEFF}

\section{$24: 3$}

\section{APPOINTMENTS VACANT}

APPIICATIONS are invited for the following appointments on or before the dates mentioned:

LECTURER IN ChEMPSTry, and a LECTURER IN PHYSICS AND MaTHEMatros-The Clfy Aworthern Polytechnic, Holloway, London, N.7 (Septemb

AsSISTANT HYSIO ST-The Superintendent, Christie Hospital and Holt Rudium Instit $1 \mathrm{e}$, Withington, Manchester 20 (September 7). AS LaTANT to THE CITY ANALYST-The Town Clerk, Civic Hall, Leeds 1, endorsed 'Asst. to the City Analyst' (September 9).

READER IN CIVIL ENGINEERING (with special interests in Hydraulics and Fluid Mechanics)-The Registrar, The University, Manchester 13 (September 9 ).

ASSISTANT Lecturer aND Demonstrator (part-time) IN PHYsics -The Secretary, King's College of Household and Social Science, Campden Hill Road, London, W.8 (September 13).

LECTURER IN PUBLIo HEALTH-The Secretary, The University, Aberdeen (September 14).

LECTURER IN ORGANIG CHEMISTRY, a LECTURER Or ASSISTANT LeCTURer IN Zoology, an ASSISTANT LeCTURER IN PHYsios, an ASSISTANT LEOTORER (OT LECTURER) IN CHEMISTRY, and a TECHNICIAN FOR THE ZOOLOGY LABORATORY - The Registrar, University College, Southampton (September 14).

LECTURER IN APPIIED MATHEMATICS and LECTURERS IN THE DEPARTMENT of PHYsics-The Registrar, The University, Liverpool (September 14).

SENIOR PRINCIPAi ScIentific OFfiokr (Senior Mechanical Development and Design Engineer), a SENIOR Principal ScIentific OFFICER or PRINCIPAL SOIENTIFIC OFHICER (Senior Electrical Design Engineer) and PRITCTPAI SCIENTIFIC OFFICERS (Mechanical Design Engineer), and PRINCIPAL SCIENTIFIC OFFICERS Mechanical Design Engineers), at the Atomic Energy Research Establishment, Harwell, dens, London, W.1, quoting No. 1613 (September 15)

dens, London, W.1, quoting No. 1613 (September 15), The University, ASSISTANT LECTURRR I
Reading (September 16).

ChaIr of Theoretical Physics, tenable at King's College, and a READER IN EXPERIMENTAL PHYSICS-The Academic Registrar, University of London, Senate House, London, W.C.1 (September 16). ASSISTANT LECTURER IN GEOLOGY-The Registrar, The University, Reading (September 16).

SENIOR ENGINEKR, Power Section, Design and Installation Department of the B.B.C., London--The Engineering Establishment Officer, Broadcasting House, London, W.1 (September 18). 